\title{
Mesoporous Carbonaceous Material From Expanded Polystyrene and Bentonite for Instantaneous Degradation of Mixture of Dyes
}

N G Salini

Nehru Arts and Science College

K.M. Muhammad Ismayil

Nirmalagiri College

Rosy Antony ( $\nabla$ drrosy.antony3@gmail.com )

Nirmalagiri College https://orcid.org/0000-0002-3342-8754

\section{Research Article}

Keywords: Bentonite, pyrolysis, carbonaceous material, dye mixture, photo catalysis

Posted Date: June 10th, 2021

DOl: https://doi.org/10.21203/rs.3.rs-589419/v1

License: (c) This work is licensed under a Creative Commons Attribution 4.0 International License.

Read Full License 


\section{Mesoporous Carbonaceous Material from Expanded Polystyrene and Bentonite for Instantaneous Degradation of Mixture of Dyes}

N G Salini ${ }^{\mathrm{a}, \mathrm{b}}$, K.M. Muhammad Ismayil ${ }^{\mathrm{a}}$, Rosy Antony ${ }^{\mathrm{a}}$ a Post Graduate and Research Department of Chemistry, Nirmalagiri College, Kannur, Kerala,670701, India.

b Department of Chemistry, Nehru Arts and Science College, Kanhangad, Kasaragod, Kerala, 671314, India.

*Corresponding author.

E-mail address: Rosy Antony, Post Graduate and Research Department of Chemistry, Nirmalagiri College, Kannur, Kerala, 670701, India. Email: drrosy.antony3@gmail.com

Rosy Antony - https://orcid.org/0000-0002-3342-8754

N G Salini - https://orcid.org/0000-0003-4136-1841

K.M. Muhammad Ismayil - https://orcid.org/0000-0001-7560-5758 


\begin{abstract}
Carbonaceous material (SBC) was prepared from waste expanded polystyrene (EPS) and bentonite clay (BT) by pyrolysis in a tubular furnace under an inert atmosphere. The calculated average crystallite size of SBC was found to be $31.57 \mathrm{~nm}$ from XRD analysis. FE-SEM studies showed that charring has changed the smooth-surfaced EPS and globular bentonite into uneven, porous flakes structure. The EDAX mapping results proved the co-existence of $\mathrm{Al}, \mathrm{Si}, \mathrm{Fe}, \mathrm{O}, \mathrm{Na}, \mathrm{Mg}, \mathrm{Ca}$, $\mathrm{Ti}$ and $\mathrm{C}$ in $\mathrm{SBC}$. BET analysis revealed the mesoporous nature of SBC and indicated its type IV isotherm behaviour. The minute loss rate value in water confirmed the water resistance, solidity and stability of the as-prepared carbonaceous material. Photo degradation in UV light for five different dyes showed immediate degradation at a catalyst dosage of $0.01 \mathrm{~g}$ for $50 \mathrm{ml} / 10 \mathrm{ppm}$ dye solution. The instantaneous discolouration of a mixture of organic dyes in the presence of UV light with micro quantities of SBC has become a cost-effective and simple method of up-cycling waste thermocol.

Keywords: Bentonite; pyrolysis; carbonaceous material; dye mixture; photo catalysis.
\end{abstract}




\section{Introduction}

Plastic pollution has become one of the major concerns of industrialists and environmentalists. Usually, plastic wastes are disposed of by land filling or incineration. In recent years, researchers are keen to develop innovative methods for the conversion of plastic wastes into useful products. Modification of plastic waste includes de-polymerization into fresh monomer, production of liquid fuel [1], consumption as filler in construction \& road tarring [2], fabrication of degradable composites by blending with agricultural wastes, utilization as matrix polymer to prepare high-performance composites and conversion into porous adsorbents $[3,4]$.

Polystyrene(PS) has been extensively used in packaging materials, disposable cups, bottles, tumblers, lids, trays, containers, insulation and decoration. Unfortunately, the majority of these materials have a limited life-cycle thereby producing a huge amount of waste. Polystyrene products cannot be recycled commercially and are disposed of generally by land filling or incineration. Land filling of expanded polystyrene/thermocol (EPS) is not economically viable since it occupies a huge volume. Incineration of EPS gives out toxic products and may cause severe environmental pollution. Sustainable development becomes the one and only one solution for environmental problems. The eco-friendly practices can be the utilization of waste thermocol, as an ingredient for construction purposes, preparation of multifunctional composites, adhesives and modification into porous carbonaceous materials $[5,6]$. Recently many researchers have reported the conversion of plastic wastes into activated carbon products with high pore volume and large surface area [7].

Activated porous carbons are seen to be attractive since the porosity can be varied suitably by modifying the reaction conditions and starting materials [8]. Polystyrene can be converted into carbonaceous materials by different techniques [9]. EPS can be converted into activated carbon having high methane uptake capacity which shows good sorption properties due to the porous structure and high bulk density $[10,11]$. Co-pyrolysis of thermocol with biomass results in activated carbon whereas sacrificial loss of PS template yields hollow and spherical sludge carbon [12]. The coating of a thin porous carbon film from PS over metal oxide has also been reported. Activated carbon is generally regarded as a good candidate for environmental applications. The porous structure permits organic and inorganic contaminants to get adsorbed [13].

Polymer composites filled with inorganic materials are multi-functional with unique characteristics such as good biodegradability, thermal, mechanical, optical and electrical properties compared to the individual components [14]. Commonly used inorganic fillers include clay, coal, carbon nanotubes, fullerenes, peat and silica [15]. Clays are commonly used as fillers because of their abundance and inertness [16]. Bentonite (BT) is the most important clay filler that can be added to polymers due to its good ion exchange capacity, high specific surface area, inertness, thermal stability and superior mechanical properties [17]. Bentonite contains layered structures of sedimentary rock along with non-clay minerals like quartz, calcite, feldspar, and dolomite. It consists of tetrahedral silica and aluminum octahedral sheets containing pendant $-\mathrm{OH}$ groups with montmorillonite as the chief clay mineral. Their porous structure allows pollutant molecules to get trapped into them and hence can be used as superior sorbents for environmental remediation $[18,19]$. 
Irradiation of the photo catalyst by UV or visible light causes degradation of the dye molecules into harmless and inert compounds [20]. On the other hand, adsorption is nondestructive, where toxic organic dyes are transferred from one phase to another thus causing secondary pollution which debilitates the meaning of environmental remediation [21]. Photo catalysis involves the light-induced generation of charge carriers like hydroxyl and superoxide anion radicals that degrade synthetic dyes and other organic compounds into $\mathrm{H}_{2} \mathrm{O}$ and $\mathrm{CO}_{2}$. The charge-carrier properties of the photo catalyst influence the generation of reactive oxygen species and its photo degradation efficiency. This process is also employed for the removal of organic pollutants like aromatic hydrocarbons, antibiotics, polycyclics, pesticides, persistent organic pollutants, ionic liquids, organic solvents, polymers, surfactants etc [22].

Silver doped nano metal oxides, clay/ activated carbon [23] semiconductor composites, biowastes etc have been reported to be used for the removal of synthetic dyes individually [24,25]. As industrial effluents contain a mixture of synthetic dyes and organic pollutants it would be beneficial to develop a single photo catalyst that can remove all these pollutants simultaneously [26].

The present work deals with the synthesis of carbonaceous material from waste EPS/bentonite clay and monitored its catalytic efficacy for the degradation of cationic and anionic dyes individually and in the mixture (MX). The UV light-induced degradation studies showed that SBC could be used as an excellent photo catalyst for the removal of a mixture of dyes. It is interesting to note that even micro quantities of SBC bring about instantaneous degradation of hazardous industrial dye wastes.

\section{Materials and methods}

Methylene blue, methyl orange, rhodamine $b$, congo red and malachite green dye were purchased from Merck Chemical Reagent Co. Ltd. India. Xylene and bentonite were purchased from Fisher Chemicals (Mumbai, India). Expanded polystyrene used in this study was collected from packaging materials, cleaned and chopped into smaller pieces. Millipore water was used for all the experiments. Dyes were dissolved in water to prepare stock solutions $(1.0 \mathrm{~g} / 1$ liter) and the working solutions were prepared by consecutive dilution of the stock solution.

\subsection{Preparation of EPS/ bentonite carbonaceous material (SBC)}

Waste expanded polystyrene without any previous treatment was used as a precursor for the preparation of SBC. To immobilize nano clay particles into the polystyrene matrix, bentonite (10\%) was added to the solution of EPS (15wt \%) in xylene and was stirred magnetically at $180 \mathrm{rpm}$ for $24 \mathrm{~h}$. After preliminary drying, the mixture was introduced into a tubular furnace and pyrolyzed at $500^{\circ} \mathrm{C}$, with a heating rate of $10^{\circ} \mathrm{C} \mathrm{min}-1$ under nitrogen, washed and again dried at $110^{\circ} \mathrm{C}$ for 1 day.

\subsection{Characterization}

The as-synthesized carbonaceous material was characterized by FTIR spectroscopy (AgilentTechnologies-Cary 630-ATR), XRD (Rigaku MiniFlex-600: 40 kV and 20 mA current, Japan), and FE-SEM \& EDAX (Supra 55VP FE-SEM) analysis. Thermo gravimetric analysis was done using Netzsch-STA 449-F5 (Germany), in the temperature range of $30-600^{\circ} \mathrm{C}$ at a heating rate of $10^{\circ} \mathrm{C} \mathrm{min}^{-1}$ under a nitrogen environment. BET surface area measurements were performed by using Novawin 3000e. A Jasco-V-550 
UV/Vis spectrophotometer was used to record the UV diffuse reflectance spectra. The photo catalytic degradation studies were carried out using a homemade photo reactor.

\subsection{The loss rate of SBC}

To determine the loss rate, a definite amount of SBC was put in $50 \mathrm{~mL}$ water and agitated at 150 rpm for $30 \mathrm{~min}$. Then it was filtered and dried to get a constant weight. A similar procedure was adopted to determine the loss rate of BT [27].

$$
P=\frac{M i-M f}{M i} \times 100
$$

where $\mathrm{Mi}$ and $\mathrm{Mf}$ respectively represent the initial and final masses of the absorbent in grams and $\mathrm{P}$ is the loss rate.

\subsection{Photo degradation studies}

The carbonaceous material SBC was used for the photo catalytic decomposition of $C R, R B, M B$, $\mathrm{MO}$ and $\mathrm{MG}$ dyes and their mixtures. The aqueous dye solution $(50 \mathrm{~mL})$ was stirred with $0.01 \mathrm{~g}$ catalyst for $30 \mathrm{~min}$ and kept in dark to attain equilibrium. It was cooled by water circulation after subjected to irradiation by a UV light source $(150 \mathrm{~W})$. $2 \mathrm{ml}$ sample solution was withdrawn at regular intervals of time ( $5 \mathrm{~min}$ ) and the absorbance was detected spectophotometrically. The photo degradation efficiency is calculated as,

$$
\text { Degradation efficiency }(\%)=\frac{\left(\mathrm{Co}-\mathrm{C}_{\mathrm{t}}\right)}{\mathrm{Co}} \times 100
$$

where $\mathrm{Co}$ is the initial dye concentrations $\left(\mathrm{mg}^{\mathrm{L}} \mathrm{L}^{-1}\right)$ and $\mathrm{Ct}$ is the final concentration after time $\mathrm{t}(\mathrm{min})$.

\section{Results and discussion}

\subsection{FTIR analysis}

Fig.1. shows the FTIR spectra of EPS, BT and SBC. EPS exhibits, C-H stretching at $2920 \mathrm{~cm}^{-1}, \mathrm{C}=\mathrm{C}$ stretching in the range $1490-1440 \mathrm{~cm}^{-1}$ and the substituted benzene ring peaks at 898,832 and $750 \mathrm{~cm}^{-1}$. For $\mathrm{BT}$, the bending vibration of $\mathrm{Si}-\mathrm{O}$ bonds appears around 1110 and $1050 \mathrm{~cm}^{-1}$. The bending $\mathrm{HO}-\mathrm{H}$ bond of water molecules present in the silicate matrix comes around $1600 \mathrm{~cm}^{-1}$. The $\mathrm{Si}-\mathrm{O}-\mathrm{Si}$ groups of the tetrahedral sheets in BT vibrate to give an intense and sharp band at $1035 \mathrm{~cm}^{-1}$ [28]. The deformation bands of Si-O-Al and Si-O-Si appear at 543 and $467 \mathrm{~cm}^{-1}$ respectively. The Absence of any significant peak in the FTIR spectrum of SBC except the characteristic peaks of metal-oxygen vibrations indicates its chemical inertness. It is in consistent with the report made by Ravi Kumar et al. [29]. 


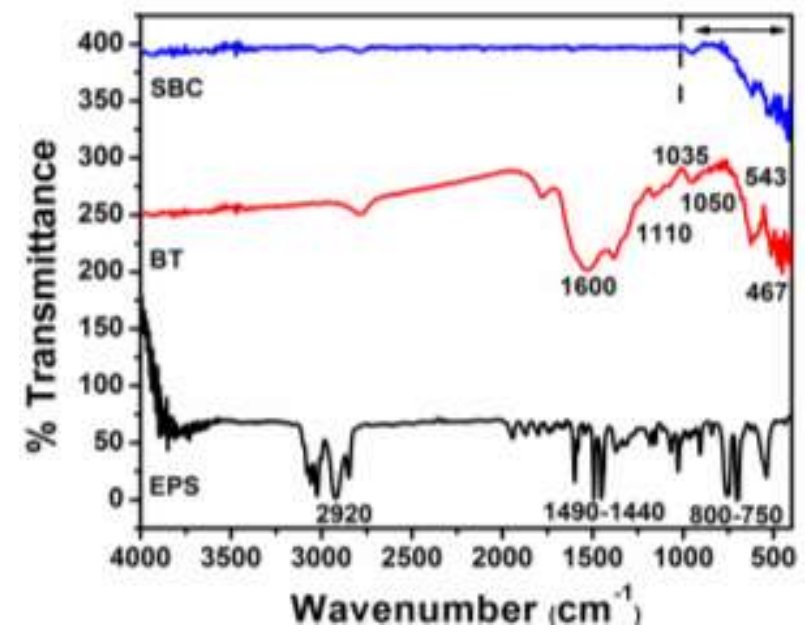

Fig.1 FTIR spectrum of EPS, BT \& SBC

\subsection{XRD analysis}

Fig.2 (a\&b) shows the XRD pattern of EPS, BT and SBC. EPS exhibits only a broad peak at $19.8^{\circ}$. The characteristic peaks of $\mathrm{BT}$ are at $\theta$ values of $11.6,19.8^{\circ}, 24.9^{\circ}, 26.5^{\circ}$ and $36.5^{\circ}$. The sharp peak at $26.5^{\circ}$ is due to the (002) lattice plane of graphite structure of carbonaceous materials. The comparison of this peak of SBC with that of BT showed that the intensity of the SBC peak was increased significantly, which indicates the presence of graphitic structure in SBC. The weak bands around $25.5^{\circ}$ and $42.3^{\circ}$ might be due to amorphous and some graphite-like structures of crystalline carbon. These observations suggest that SBC possesses an intermediate structure between graphite and amorphous state [28].
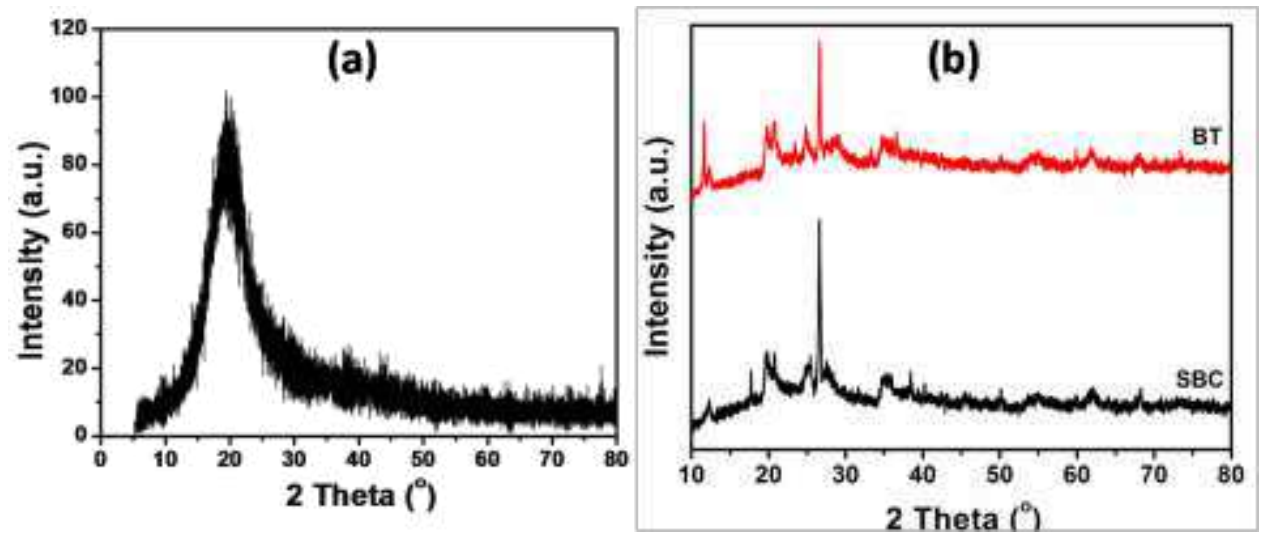

Fig.2 XRD pattern of (a) EPS, (b) BT\& SBC

The crystallite size was calculated by using the Scherer formula as;

$$
\mathrm{D}=\frac{\mathrm{k} \lambda}{\beta \cos \theta}
$$


where $D$ is the crystallite size, $\lambda$ is the $X$-ray wavelength, $k$ is a dimensionless shape factor, $\beta$ is the line broadening at half the maximum intensity, $\theta$ and is the Bragg angle. The calculated average crystallite sizes of the samples SBC and BT were 31.57 and $40.83 \mathrm{~nm}$ respectively.

\subsection{FESEM and EDAX analysis}

Fig.3 (a-e) shows the FE-SEM image of EPS, BT and SBC along with EDAX mapping results. FESEM images indicate that BT has a globular surface whereas SBC shows a non-uniform, porous, flakes-like structure. The virgin EPS film exhibits smooth surface morphology. The EDAX mapping results of selected areas of FE-SEM images prove the coexistence of $\mathrm{Al}, \mathrm{Si}, \mathrm{Fe}, \mathrm{O}, \mathrm{Na}, \mathrm{Mg}, \mathrm{Ca}, \mathrm{Ti}$ and $\mathrm{C}$ in $\mathrm{SBC}$.

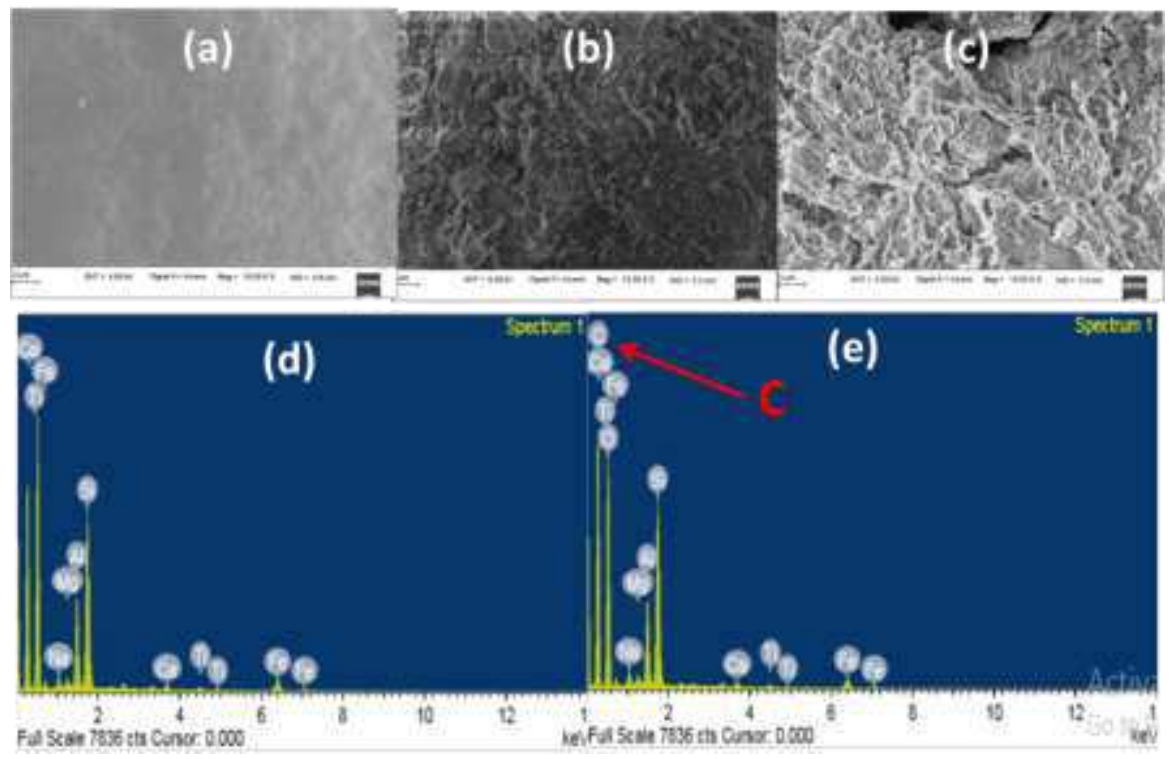

Fig.3. FE-SEM images of (a) EPS, (b) BT \& (c) SBC \& EDAX images of (d) BT \& (e) SBC

\subsection{TGA analysis}

Fig.4 (a\& b) show the TGA curves of EPS, BT and SBC. The thermo gram very well shows the higher thermal stability of SBC as it degrades in a single step with a very high char residue of $96 \%$. For EPS the initial weight loss can be due to the removal of adsorbed moisture and solvent molecules. Chain scission starts at $350^{\circ} \mathrm{C}$ and degradation is completed at $459.1^{\circ} \mathrm{C}$. The thermo gram of BT indicates two dehydration steps extending up to $450^{\circ} \mathrm{C}$. The final weight loss of $5 \%$ in the range of $420-700^{\circ} \mathrm{C}$ might be due to the condensation reaction between adjacent hydroxyl groups present in the inorganic polymer network [24]. 

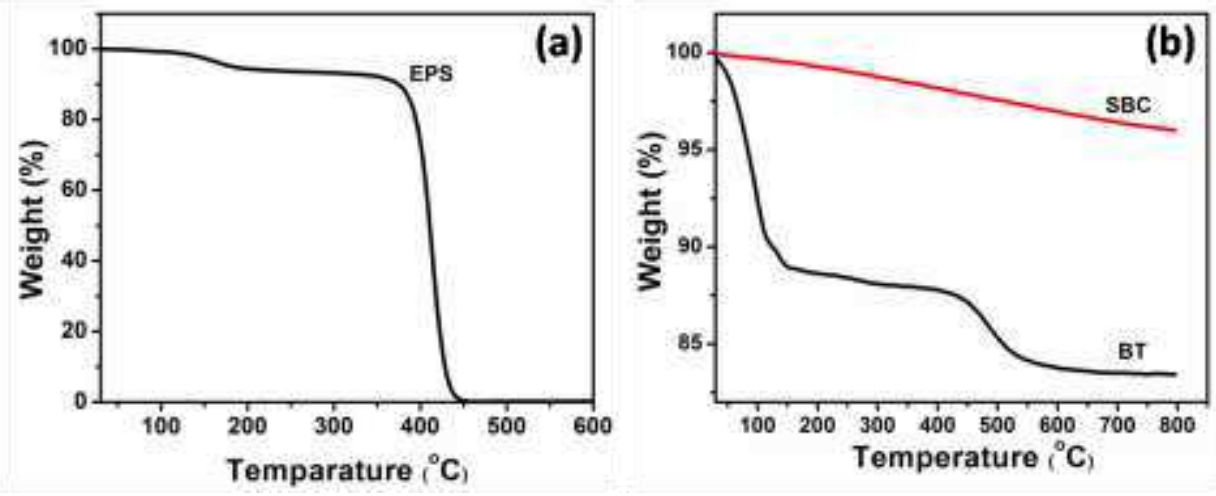

Fig.4. TGA thermo gram of (a) EPS, (b) BT \& SBC

\subsection{UV-DRS analysis}

Fig.5 (a, b\& c) shows the UV-DRS spectra and Tauc plot of EPS, BT and SBC. BT and EPS show maximum absorption at 270 and $260 \mathrm{~nm}$ respectively whereas SBC exhibits a peak at $\lambda$ max value of $330 \mathrm{~nm}$. The absorption peaks and band structures of SBC have shown red shift due to the combined effect of the metal oxides present in it [30]. The band gap energy was calculated by the Tauc plot. The optical absorption follows the equation:

$$
(\alpha h u)=A(h u-E g)^{1 / 2}
$$

where $\alpha, h, v, E g$, and A are the absorption coefficient, Plank constant, light frequency, band gap energy, and a constant respectively.

The Eg value was obtained by extrapolating the linear portion of the curve $(\alpha h u)^{2}$ versus $h v$ to zero. The band gap energy values of EPS, BT and SBC were obtained as 2.98, 2.06 and $1.78 \mathrm{eV}$ respectively. Band gap energy affects the degradation efficiency of the photo catalyst. The reduction in Eg value in the case of SBC was due to crystal defects in the system, which gives rise to Fermi energy level. Electronic transitions occur to Fermi energy level from the valence band. Hence photon- induced charge carriers were generated. This results in the production of free radicals, which attack the dye molecules [31]. 

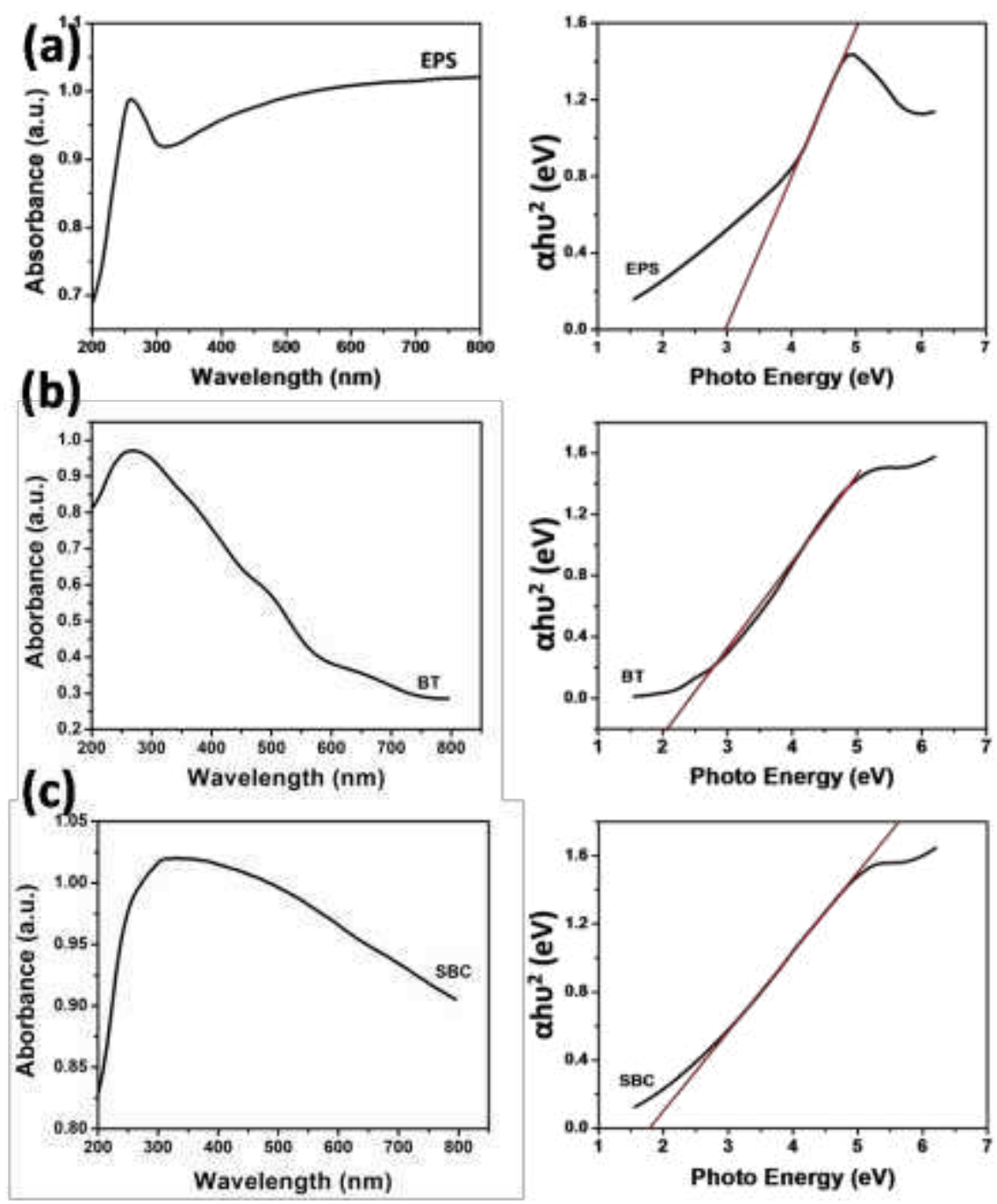

Fig.5.UV-DRS spectra \& Tauc plot of (a) EPS, (b) BT \& (c) SBC

\subsection{BET surface area and pore size analysis.}

BET analysis was performed by the $\mathrm{N}_{2}$ adsorption-desorption experiments conducted at $77 \mathrm{~K}$ [32]. SBC exhibited type IV isotherm and adsorption behaviour is characteristic of mesoporous materials as shown in Fig.6. The total pore volume, surface area and average pore diameter of SBC were found to be $0.0188 \mathrm{~cm}^{3} / \mathrm{g}, 11.875 \mathrm{~m}^{2} \mathrm{~g}^{-1}$ and $4.38 \mathrm{~nm}$ respectively [33]. 


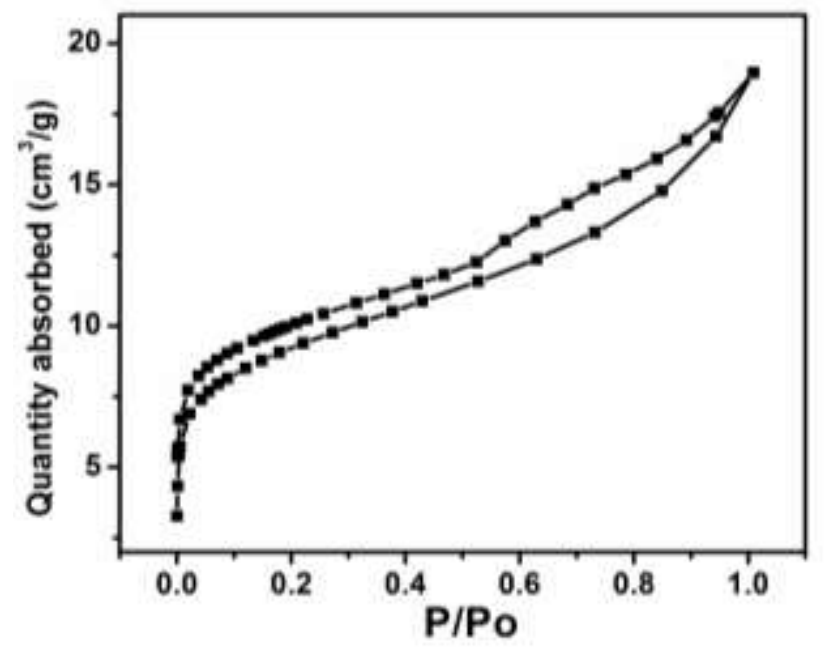

Fig. 6.Nitrogen adsorption/desorption isotherms for SBC

\subsection{Optimization of parameters}

The effect of catalyst dosage and $\mathrm{pH}$ on photo degradation efficiency of SBC was studied.

Different amounts of SBC $(5-50 \mathrm{mg} / 50 \mathrm{~mL})$ were used to study the effect of adsorbent dosage on the photo degradation of dyes and are shown in Fig.7 (a). The degradation efficiency increased with SBC dosage and exhibited significant percentage degradation even with $10.0 \mathrm{mg}$ and hence, a dosage of $10.0 \mathrm{mg} / 50 \mathrm{ml}$ was taken as the optimum concentration.

Fig.7 (b) shows the influence of $\mathrm{pH}$ on the degradation of a mixture of dyes. It can be seen that the percentage discolouration was maximum at $\mathrm{pH}$ 7. The degradation efficiency was found to decrease above and below this $\mathrm{pH}$ due to the presence of both cationic and anionic charge centers in the dye mixture [34].
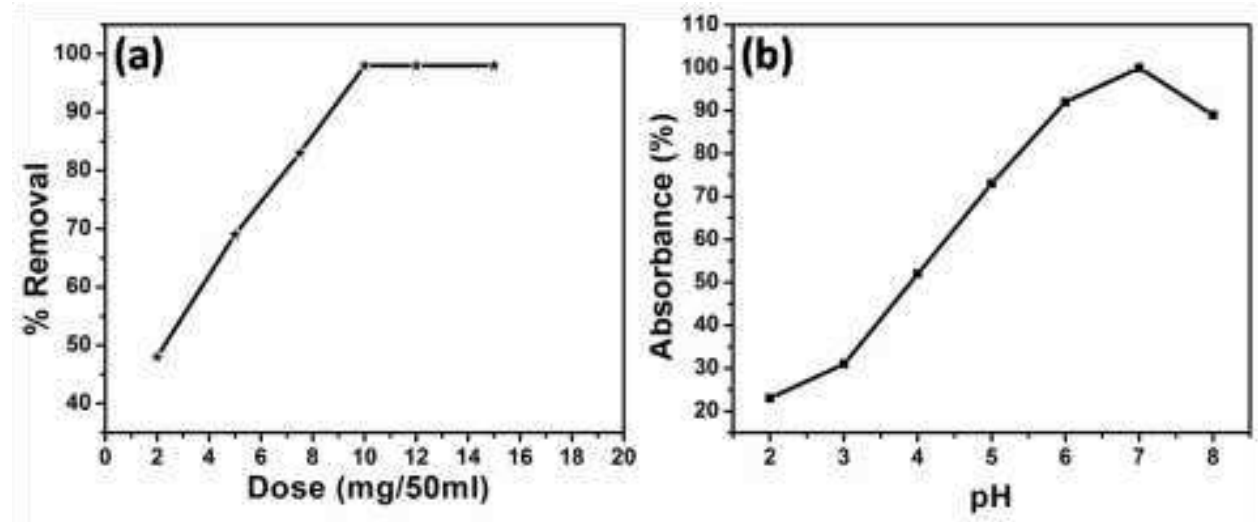

Fig.7 Effect of (a) SBC dose \& (b) pH on degradation 


\subsection{Loss rate}

Fig.8 (a) compares the mass loss rate of SBC with pristine BT in water. It can be seen that the mass loss rate of $\mathrm{SBC}$ is negligible compared to $\mathrm{BT}$ which indicates the water resistance, solidity, and stability of the as-prepared carbonaceous material.

\subsection{Reusability of the photo catalyst}

To study the reusability of SBC, the photo degradation experiment was repeated many times with the same catalyst. Fig.8 (b) illustrates the degradation efficiency of SBC for all five dyes and their mixture. The percentage degradation values were found to be $97,97,96.5,96,94 \& 93 \%$ respectively for $M B, M G, C R, R B, M O \& M X$ even after three cycles. These results indicate the stability and suitability of $\mathrm{SBC}$ as a promising photo catalyst.
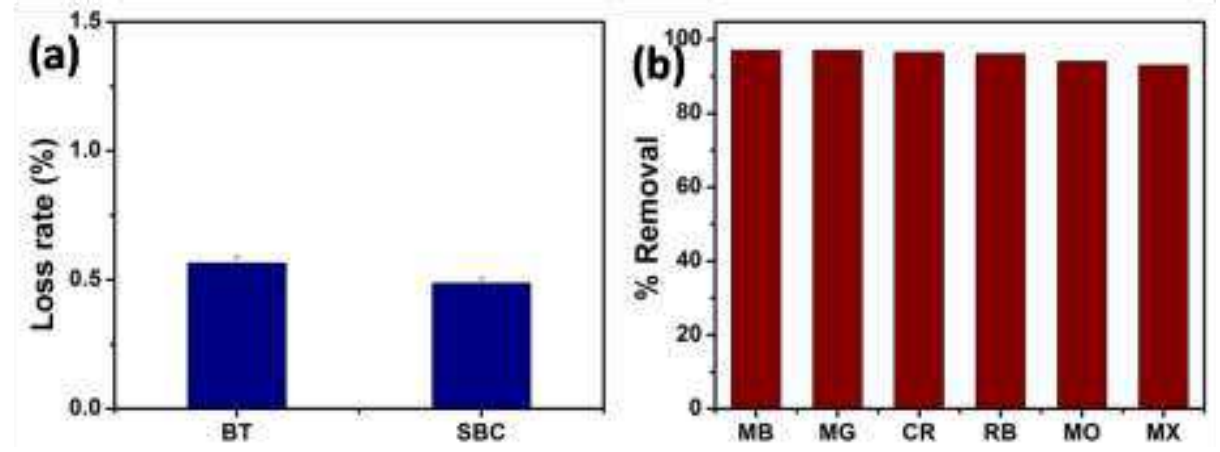

Fig.8 (a) Loss rate \& (b) Reusability of SBC

\subsection{Photo catalytic studies}

The photo degradation efficiency of SBC under optimum conditions of catalyst dosage, $\mathrm{pH}$ and dye concentration was monitored using UV-Visible absorption spectroscopy. Fig.9 illustrates the degradation efficiency of SBC for the dissociation of $M B, R B, C R, M G$ and $M O$ and their mixture. $A$ decrease in absorption maximum is accompanied by the colour change indicating the dissociation of the dye molecule. Decomposition involves the breakup of the chromophore [35]. Discolouration was completed within 5 min for MB \& MG 10 mins for CR \& RB and 15 min for MO and MX (dye mixture). Even a catalyst dosage of $0.01 \mathrm{~g}$ was sufficient for the dissociation of $50 \mathrm{ml}$ of dye solutions in individual and in the mixture, it points towards the superior degradation efficiency of SBC. Fig.10 shows the UVVis absorption spectra and photographic images of dyes and dye mixture before and after photo degradation. The characteristic absorption peaks ( $\lambda \max$ ) of $M B, R B, C R, M G$ and $M O$ are at 662,554 , 497,615 and $460 \mathrm{~nm}$ respectively. 


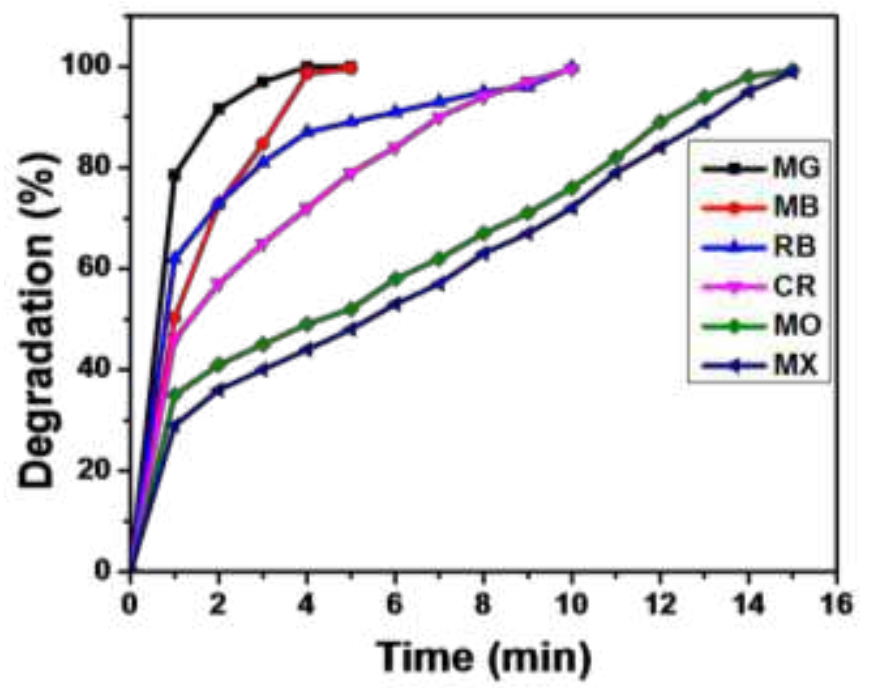

Fig.9. Degradation efficiency of dyes 

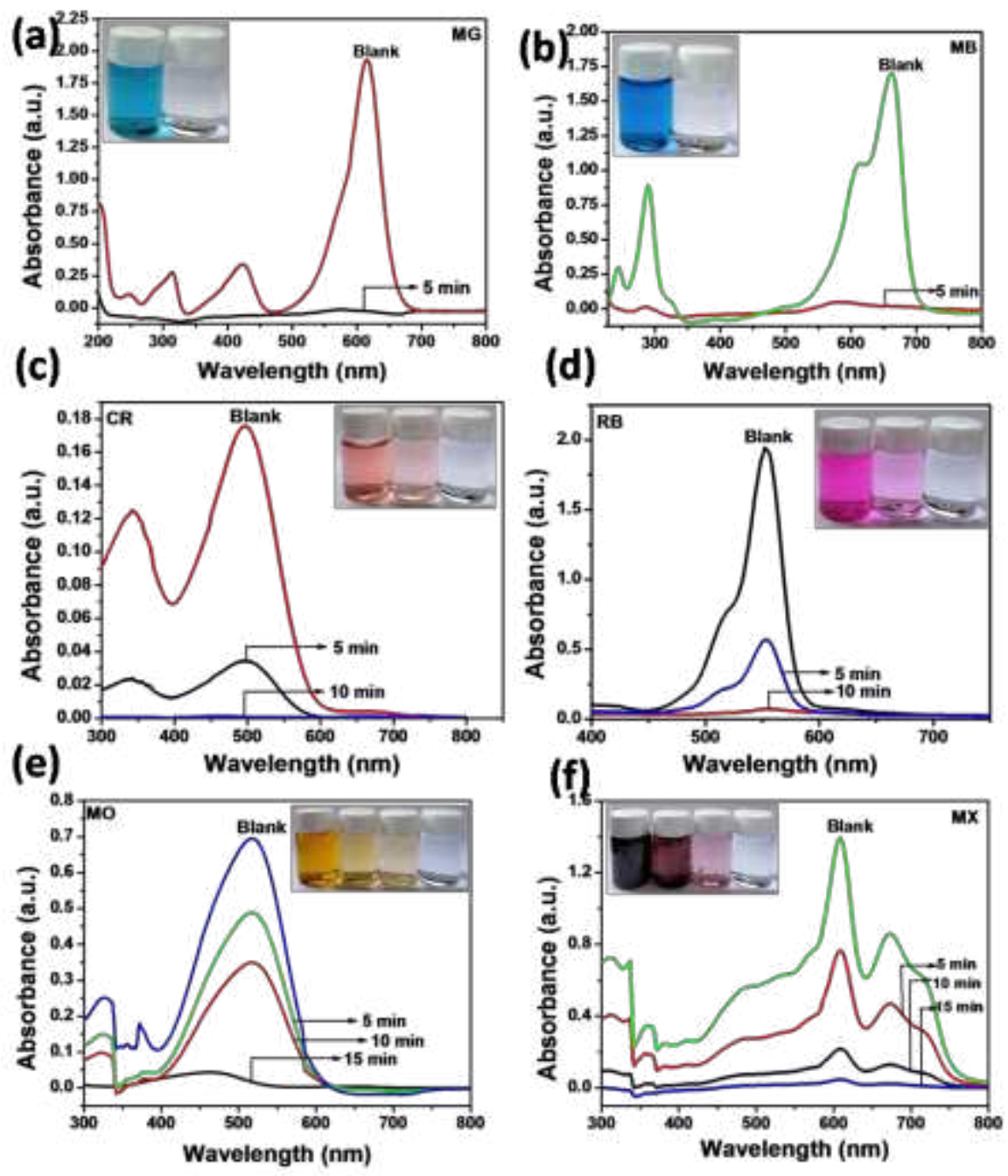

Fig.10. UV-Vis absorption spectra and photographic images of (a) MG, (b) MB, (c) CR, (d) RB, (e) MO \& (f) MX dyes

\subsection{Photo catalytic mechanism}

It is well known that charcoal and other carbonaceous materials are very good adsorbents and also the adsorbed materials can be easily desorbed by using acids, alkalies, chelating agents etc. But it was found that even a trace of dye material didn't come out from SBC to any of these media. Hence the decolouration of dye solutions occurs by degradation [36]. Fig.11. shows the proposed mechanism for photo catalysis.

Electrons and holes are generated by illumination of UV light on the metal oxides present in SBC. By leaving behind holes, the electrons are promoted from the valence band to the conduction band. These electrons convert molecular oxygen to superoxide radical anions and holes in the valence band convert water molecules to hydroxyl radicals. The charge transfer processes are responsible for 
the UV-light-induced degradation of dye. The superoxide radical anions and hydroxyl radicals attack the vulnerable part of the dye and mineralize into $\mathrm{CO}_{2}$ and $\mathrm{H}_{2} \mathrm{O}$ through a radical-chain mechanism $[37,38]$.

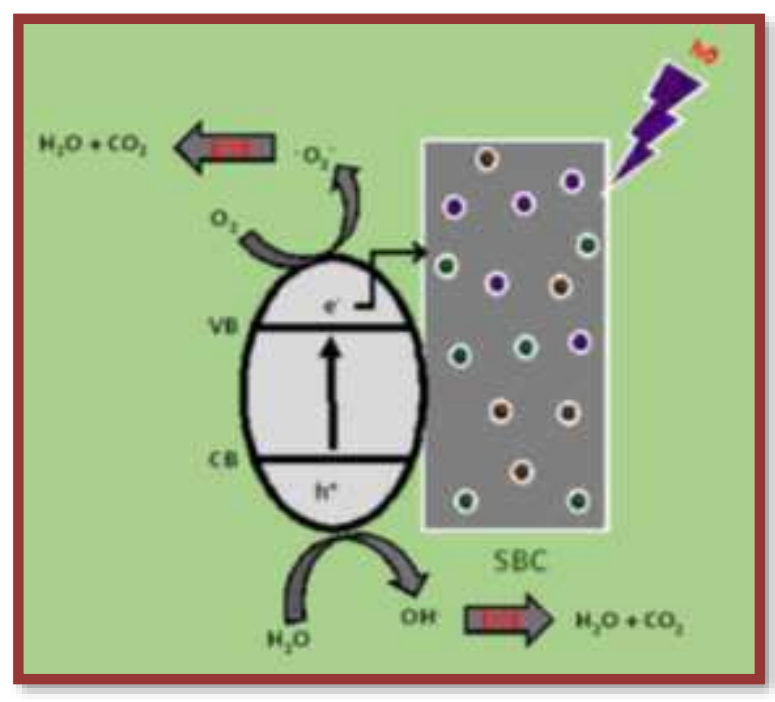

Fig.11.Proposed mechanism of photo degradation

\subsection{Kinetics of degradation}

The photo catalytic degradation was found to follow the Langmuir- Hinshelwood kinetic equation;

$$
\ln \frac{C o}{C t}=K t
$$

where $\mathrm{Co}$ and $\mathrm{Ct}$ are the initial and final concentration $\left(\mathrm{mg} \cdot \mathrm{L}^{-1}\right)$ of the dye at time $\mathrm{t}, \mathrm{K}$ is the pseudo- first-order reaction rate constant $\left(\mathrm{min}^{-1}\right)$. Fig.12. shows the plot of In Co/Ct versus $\mathrm{t}$. It can be seen that the large surface area of the porous carbonaceous material facilitates the high rate of photo degradation and the kinetic parameters are given in Table.1. The higher photo degradation rate constant ensured the Langmuir Hinshelwood kinetics [39]. 

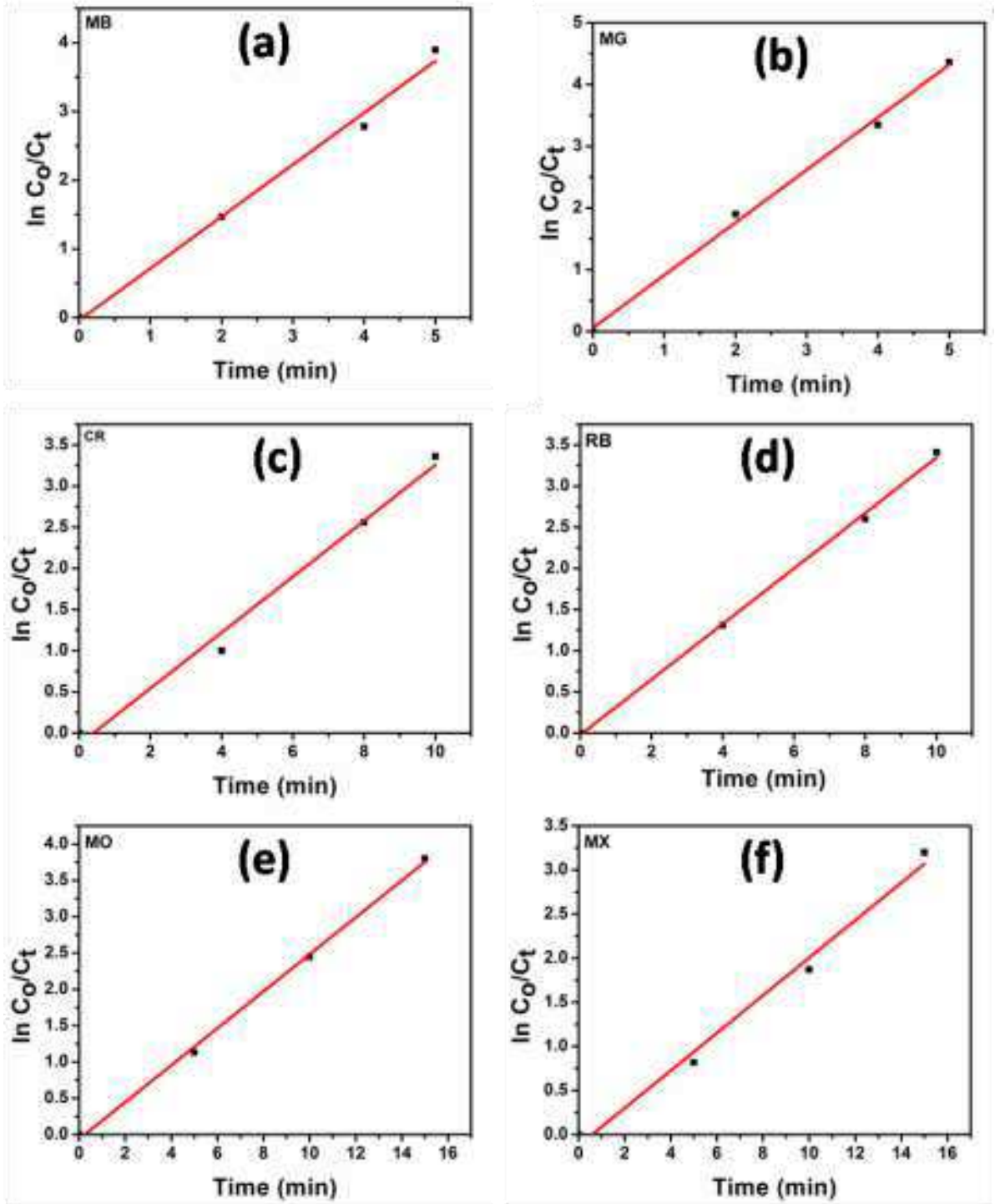

Fig.5.12. Kinetic plots of (a) MB, (b) MG, (c) CR, (d) RB,

(e) $M O \&(f) M X$ 
Table.1. Kinetic parameters

\begin{tabular}{cccc}
\hline Sample & Dye & $\begin{array}{c}\text { Rate constant } \\
\mathrm{K}\left(\mathrm{min}^{-1}\right)\end{array}$ & $\mathrm{R}^{2}$ values \\
\hline \multirow{6}{*}{$\mathrm{SBC}$} & $\mathrm{MG}$ & 0.8525 & 0.9947 \\
& $\mathrm{MB}$ & 0.7553 & 0.9880 \\
& $\mathrm{RB}$ & 0.3412 & 0.9977 \\
& $\mathrm{CR}$ & 0.3393 & 0.9829 \\
& $\mathrm{MO}$ & 0.2545 & 0.9975 \\
& $\mathrm{MX}$ & 0.2130 & 0.9829 \\
\hline
\end{tabular}

\section{Conclusion}

Waste expanded polystyrene was pyrolyzed with bentonite clay in a tubular furnace under a nitrogen atmosphere to get the carbonaceous material, SBC. The FTIR analysis revealed its chemical inertness and XRD analysis indicated partial crystallinity. FE-SEM studies showed the non-uniform, porous, flakes-like structure of SBC. The EDAX mapping results proved the co-existence of $\mathrm{Al}, \mathrm{Si}, \mathrm{Fe}, \mathrm{O}$, $\mathrm{Na}, \mathrm{Mg}, \mathrm{Ca}$, Ti and $\mathrm{C}$ in SBC. BET analysis revealed the mesoporous nature of SBC and indicated its type IV isotherm behaviour. The negligible loss rate value confirmed the water resistance, solidity and stability of the as-prepared carbonaceous material.

The degradation efficiency of SBC was studied for the photo catalytic dissociation of $M G, M B$, $\mathrm{RB}, \mathrm{CR} \& \mathrm{MO}$ dyes and their mixture; the conditions were optimized as-catalyst dosage of $0.01 \mathrm{~g}$ for $10 \mathrm{mg} / 50 \mathrm{ml}$ dye solution at $\mathrm{pH} 7$. SBC exhibited superior percentage degradation values even after three cycles $(97,97,96.5,96,94$ \& 93\% respectively for MB, MG, CR, RB, MO \& MX) indicating the stability and suitability of SBC as a potential photo catalyst. The instantaneous discolouration of the mixture of organic dyes in UV light with micro quantities of SBC has become a cost-effective and simple method of up cycling waste thermocol. It is a green chemistry strategy as it eliminates the usage of toxic chemicals and promotes the utilization of waste expanded polystyrene for environmental remediation.

\section{Declarations}

\section{Funding}

No funds, grants, or other support was received.

\section{Conflicts of interest/ Competing interests}

All authors certify that they have no affiliations with or involvement in any organization or entity with any financial interest or non- financial interest in the subject matter or materials discussed in this manuscript.

\section{Availability of data and material}

All data generated or analyzed during this study are included in this published article.

\section{Code availability}


Not applicable.

\section{Author's contributions}

All authors contributed to the study conception and design. Material preparation, data collection and analysis were performed by N G Salini, K.M. Muhammad Ismayil and Rosy Antony. All authors read and approved the final manuscript

\section{Ethics approval}

The submitted work was original and should not have been published elsewhere in any form or language (partially or fully). Results were presented clearly, honestly and without fabrication or inappropriate data manipulation. Authors adhered to discipline- specific rules for acquiring, selecting and processing data.

\section{References}

[1] S. Budsaereechai, A. J. Hunt, and Y. Ngernyen, (2019) RSC Adv., 9, 5844-5857, doi: 10.1039/c8ra10058f.

[2] N. Nciri, T. Shin, and N. Cho, (2020) Mater. Today Proc., 24, 763-771, doi: 10.1016/j.matpr.2020.04.384.

[3] K. L. Hsu, (2019) IOP Conf. Ser. Earth Environ. Sci., 351, 1-11, doi: 10.1088/17551315/351/1/012021.

[4] T. Morishita, Y. Soneda, T. Tsumura, and M. Inagaki, (2006) Carbon, 44, 2360-2367, doi: 10.1016/j.carbon.2006.04.030.

[5] Stuart Ross, David Evans (2003) J. Clean. Prod., 11, 561-571, doi: doi:10.1016/S09596526(02)00089-6.

[6] R. C. Thompson, C. J. Moore, F. S. V. Saal, and S. H. Swan, (2009) Philos. Trans. R. Soc. B Biol. Sci., 364, 1526, 2153-2166, doi: 10.1098/rstb.2009.0053.

[7] S. M. Al-Salem, P. Lettieri, and J. Baeyens, (2009) Waste Manag., 29, 2625-2643, doi: 10.1016/j.wasman.2009.06.004.

[8] M. Adibfar, T. Kaghazchi, N. Asasian, and M. Soleimani, (2014) Chem. Eng. Technol., 37, 979-986, doi: 10.1002/ceat.201200719.

[9] G. Gatti et al., (2019) Nanomater., 1-13, doi: 10.3390/nano9050726.

[10] F. G. F. de Paula, M. C. M. de Castro, P. F. R. Ortega, C. Blanco, R. L. Lavall, and R. Santamaría, (2018) Microporous Mesoporous Mater., 267, 181-184, doi: 10.1016/j.micromeso.2018.03.027.

[11] T. Hu et al., (2020) ACS Omega, doi: 10.1021/acsomega.9b03743.

[12] P. Sekhar et al., (2017) Ceram. Int., doi: 10.1016/j.ceramint.2017.09.194.

[13] X. He, K. B. Male, P. N. Nesterenko, D. Brabazon, B. Paull, and J. H. T. Luong, (2013) ACS Appl. Mater. Interfaces, 5, 8796-8804.

[14] X. L. Xie et al., (2004) Polymer, 45, 19, 6665-6673, doi: 10.1016/j.polymer.2004.07.045.

[15] M. A. Motawie, N. M. Ahmed, S. M. Elmesallamy, E. M. Sadek, and N. G. Kandile, (2014) J. Appl. Chem., 7, 34-43.

[16] O. R. O. Aroke U.O., Abdulkarim A., (2013) J. Environ. Technol., 6, 42-53.

[17] O. V Alekseeva, A. N. Rodionova, N. A. Bagrovskaya, A. V Noskov, and A. V Agafonov, (2018)" Iran. Polym. J., doi: 10.1007/s13726-018-0683-9.

[18] L. Zhang, H. Zhang, W. Guo, and Y. Tian, (2014) Appl. Clay Sci., 93-94, 85-93, doi: 10.1016/j.clay.2014.03.004. 
[19] A. T. Babu, R. Antony, (2019) J. of Environ Chem. Eng., 7, doi: 10.1016/j.jece.2018.102840.

[20] A. K. Sarkar, A. Saha, A. Tarafder, A. B. Panda, and S. Pal, (2016) ACS Sustain. Chem. Eng., 4, 1679-1688, doi: 10.1021/acssuschemeng.5b01614.

[21] P. Samanta, A. V. Desai, S. Let, and S. K. Ghosh, (2019) ACS Sustain. Chem. Eng., 7, 7456-7478, doi: 10.1021/acssuschemeng.9b00155.

[22] K. P. Priyanka, S. Sankararaman, K. M. Balakrishna, and T. Varghese, (2017) J. Alloys Compd., 720, 541-549, doi: 10.1016/j.jallcom.2017.05.308.

[23] P. Raizada et al., (2014) Appl. Catal. A Gen., 486, 159-169, doi: 10.1016/j.apcata.2014.08.043.

[24] G. A. Seilkhanova, A. N. Imangaliyeva, Y. Mastai, and A. B. Rakhym, (2019) Bull. Mater. Sci., 42, 18, doi: 10.1007/s12034-019-1752-1.

[25] M. Kunnamareddy, B. Diravidamani, R. Rajendran, B. Singaram, and K. Varadharajan, (2018) J. Mater. Sci. Mater. Electron., 29, 18111-18119, doi: 10.1007/s10854-018-9922-2.

[26] M. Chandhru, S. K. Rani, and N. Vasimalai, (2020) J. Environ. Chem. Eng., 8, 104225, doi: 10.1016/j.jece.2020.104225.

[27] G. Xin, M. Wang, L. Chen, Y. Zhang, and M. Wang, (2019) RSC Adv., 1, 6452-6459, doi: 10.1039/c8ra08800d.

[28] A. T. Babu and R. Antony, (2019) Appl. Clay Sci., 183, 105312, doi: 10.1016/j.clay.2019.105312.

[29] R. Kumar, M. Mamlouk, and K. Scott, (2011) Int. J. Electrochem., 1-7, 2011, doi: 10.4061/2011/434186.

[30] Ö. A. Yildirim, H. E. Unalan, and C. Durucan, (2013) J. Am. Ceram. Soc., 96, 766-773, doi: 10.1111/jace.12218.

[31] A. D. Acharya, B. Sarwan, R. Sharma, S. Moghe, S. B. Shrivastava, and V. Ganesan, (2017) J. Phys. Conf. Ser., 836, , doi: 10.1088/1742-6596/836/1/012048.

[32] S. Brunauer, P. H. Emmett, and E. Teller, (1938) J. Am. Chem. Soc., 60, 309-319, doi: 10.1021/ja01269a023.

[33] R. Ashouri et al., (2019) J. Environ. Chem. Eng., 7, 14552-14571, doi: 10.1016/j.jece.2020.104364.

[34] M. M. Sabzehmeidani, H. Karimi, and M. Ghaedi, (2018) Appl. Organomet. Chem., 32, 1-15, doi: 10.1002/aoc.4335.

[35] Z. Sun, Y. Chen, Q. Ke, Y. Yang, and J. Yuan, (2002) J. Photochem. Photobiol. A Chem., 149, 169174, doi: 10.1016/S1010-6030(01)00649-9.

[36] R. Ashouri, P. Ghasemipoor, B. Rasekh, F. Yazdian, S. R. Mofradnia, and M. fattahi, (2019) Int. J. Environ. Sci. Technol., 16, 1729-1740, doi: 10.1007/s13762-018-2056-5.

[37] S. Acharya, S. Martha, P. C. Sahoo, and K. Parida, (2015) Inorg. Chem. Front., 2, 807-823, , doi: 10.1039/c5qi00124b.

[38] K. Peng et al., (2018) Appl. Clay Sci., 175, 86-93, 2019, doi: 10.1016/j.clay.2019.04.007.

[39] S. Wunder, F. Polzer, Y. Lu, Y. Mei, and M. Ballauff, (2010) J. Phys. Chem. C, 114, 8814-8820, doi: 10.1021/jp101125j. 
Figures

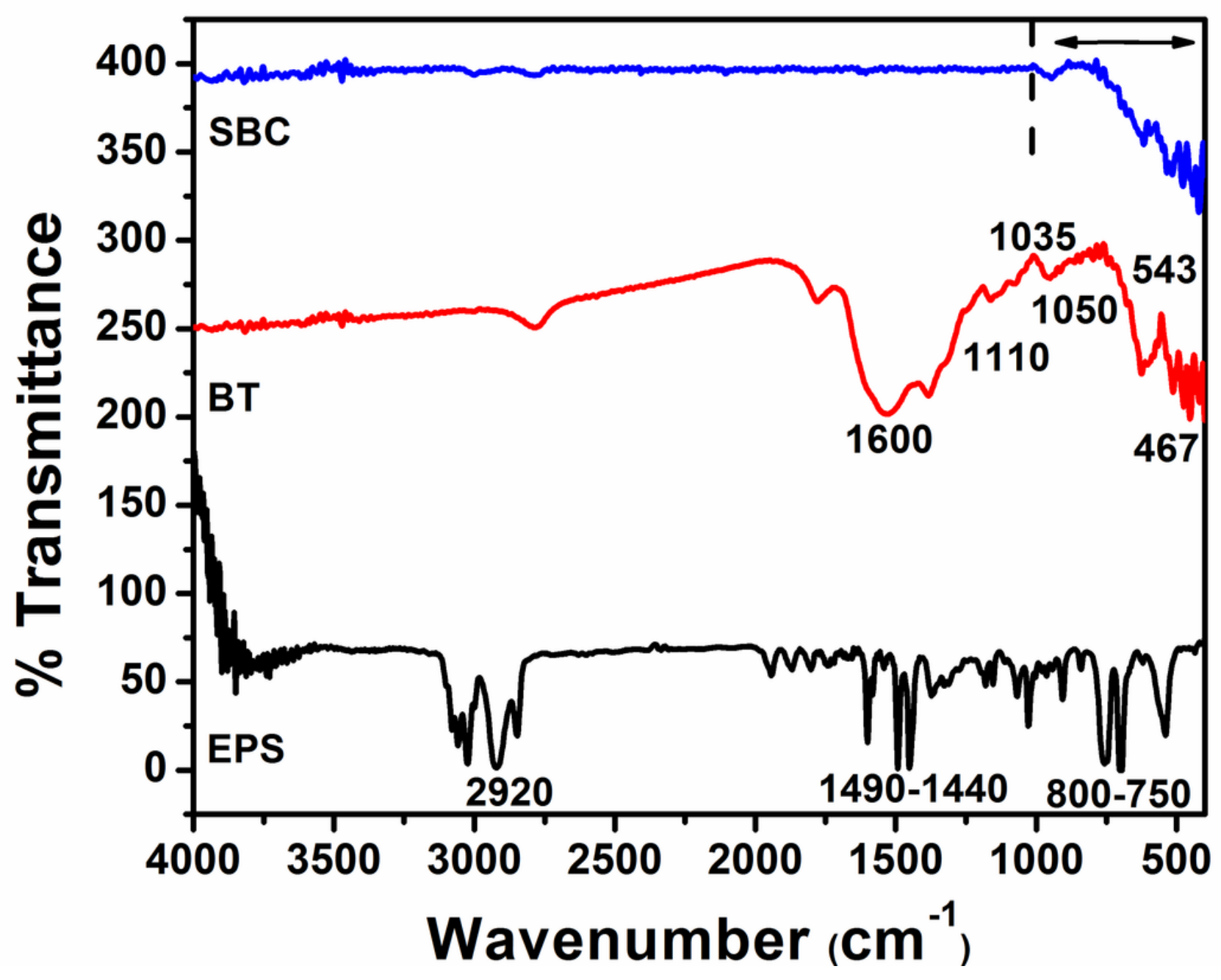

Figure 1

FTIR spectrum of EPS, BT \& SBC 

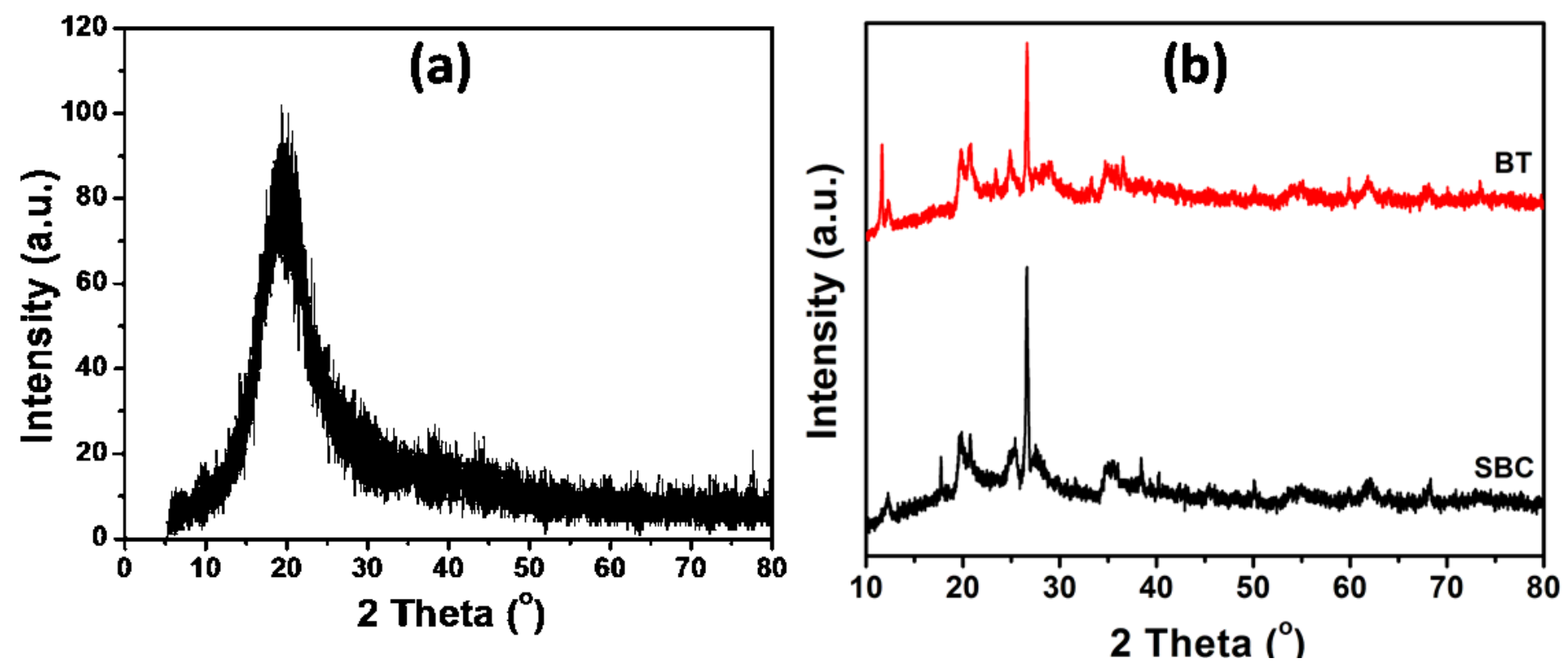

Figure 2

XRD pattern of (a) EPS, (b) BT\& SBC

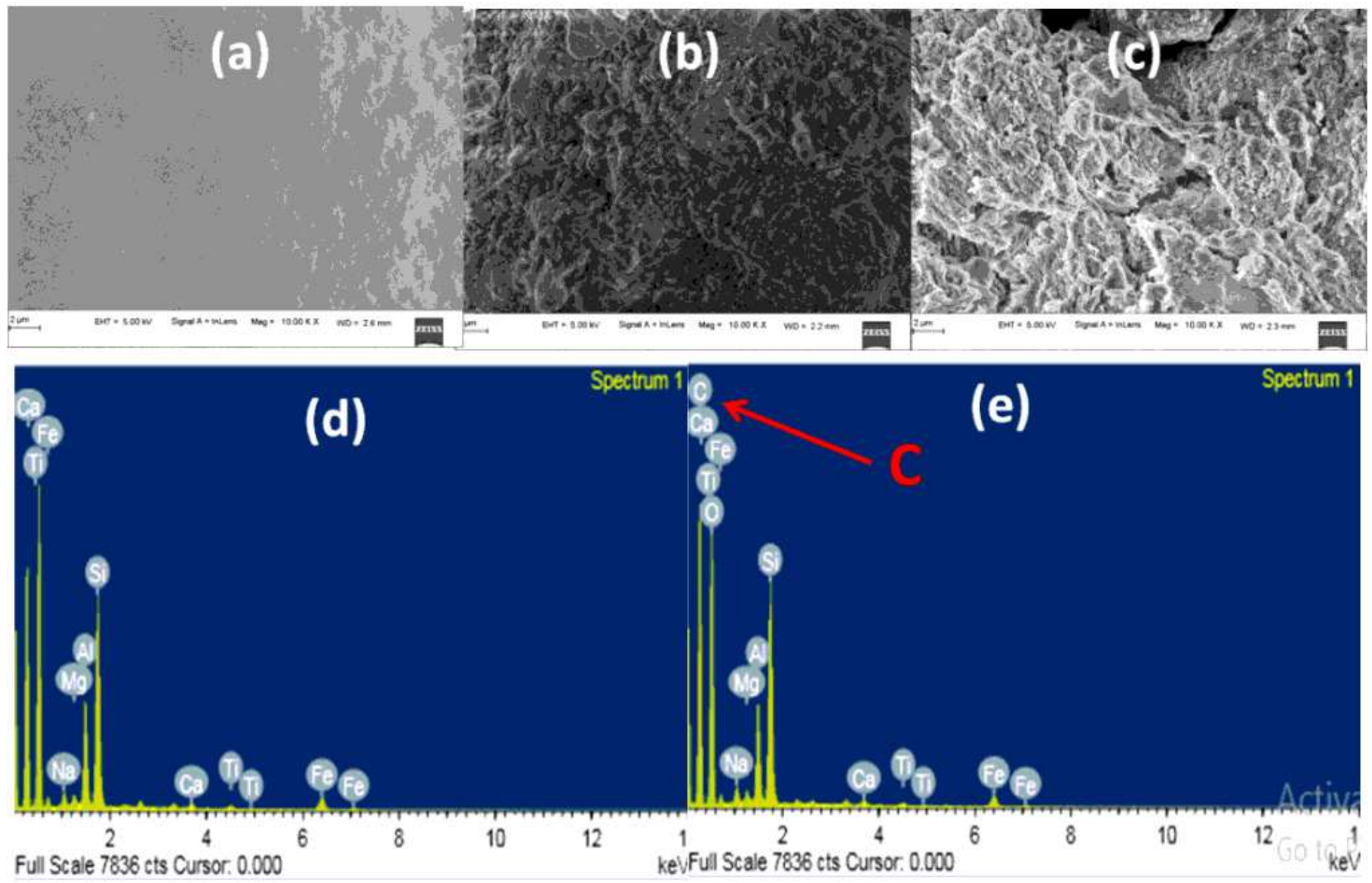

Figure 3 
FE-SEM images of (a) EPS, (b) BT \& (c) SBC \& EDAX images of (d) BT \& (e) SBC
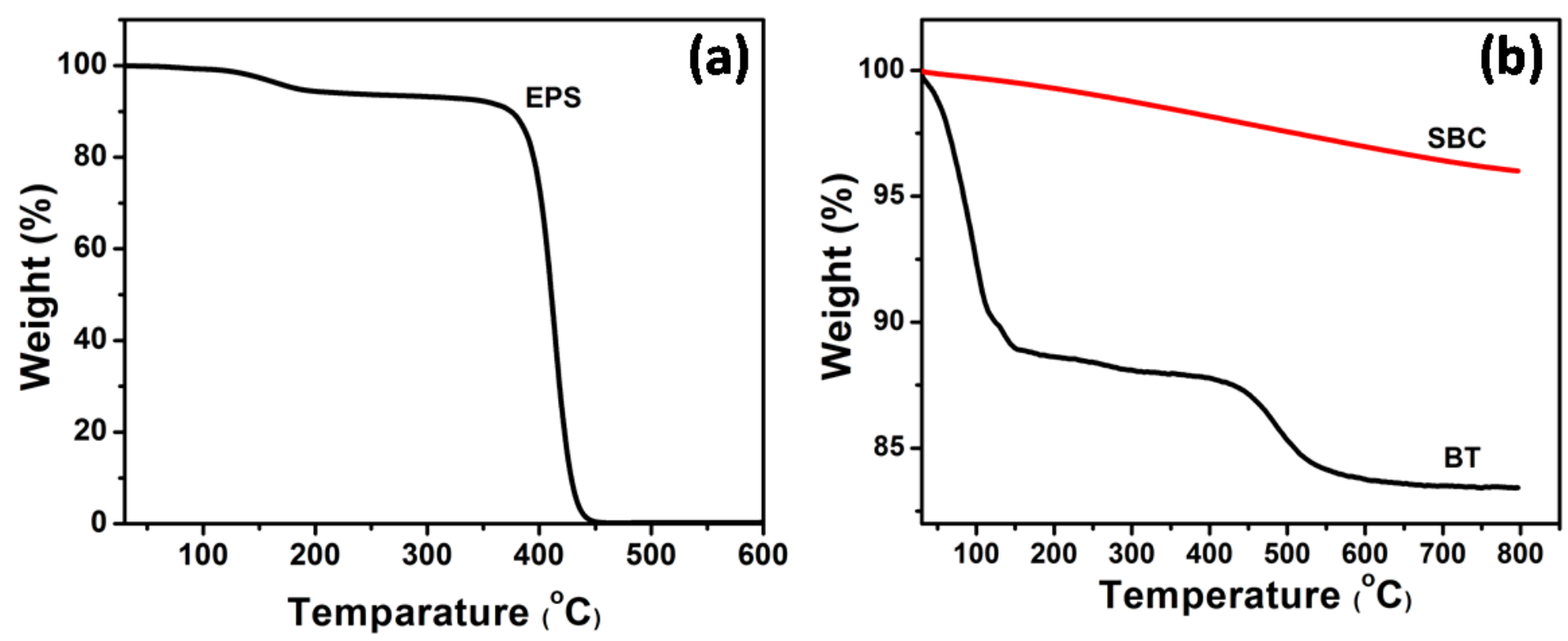

Figure 4

TGA thermo gram of (a) EPS, (b) BT \& SBC 

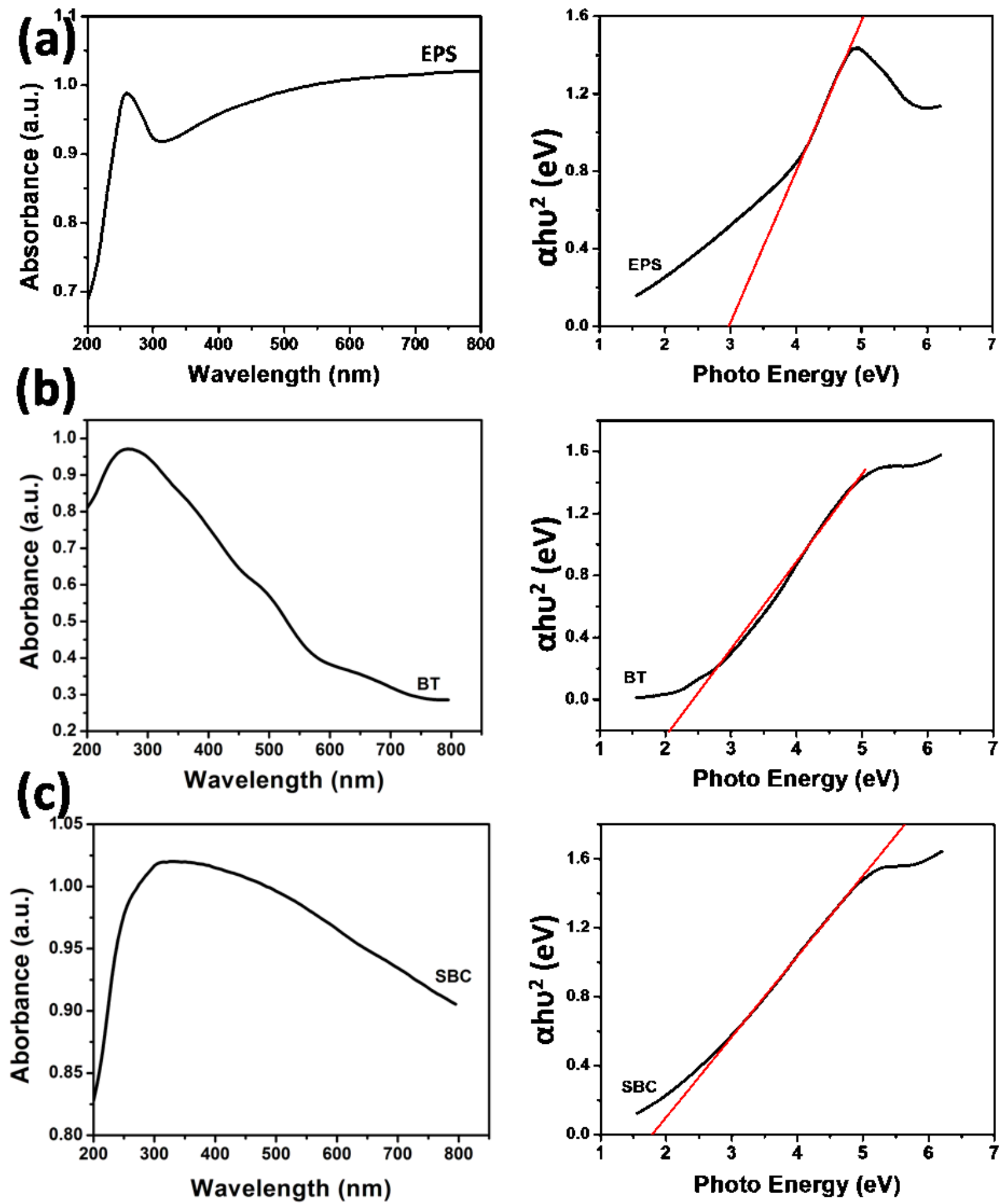

Figure 5

UV-DRS spectra \& Tauc plot of (a) EPS, (b) BT \& (c) SBC 


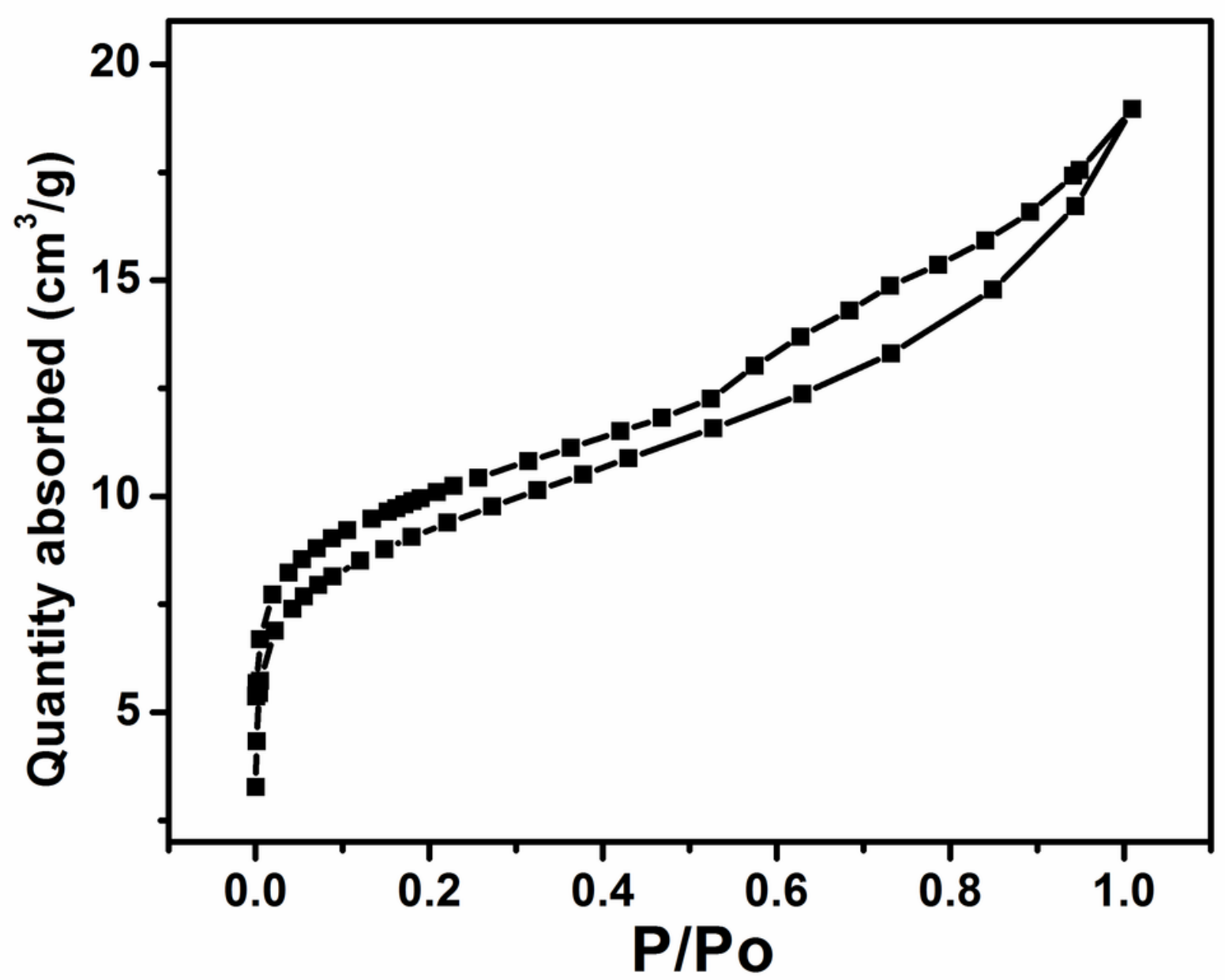

Figure 6

Nitrogen adsorption/desorption isotherms for SBC
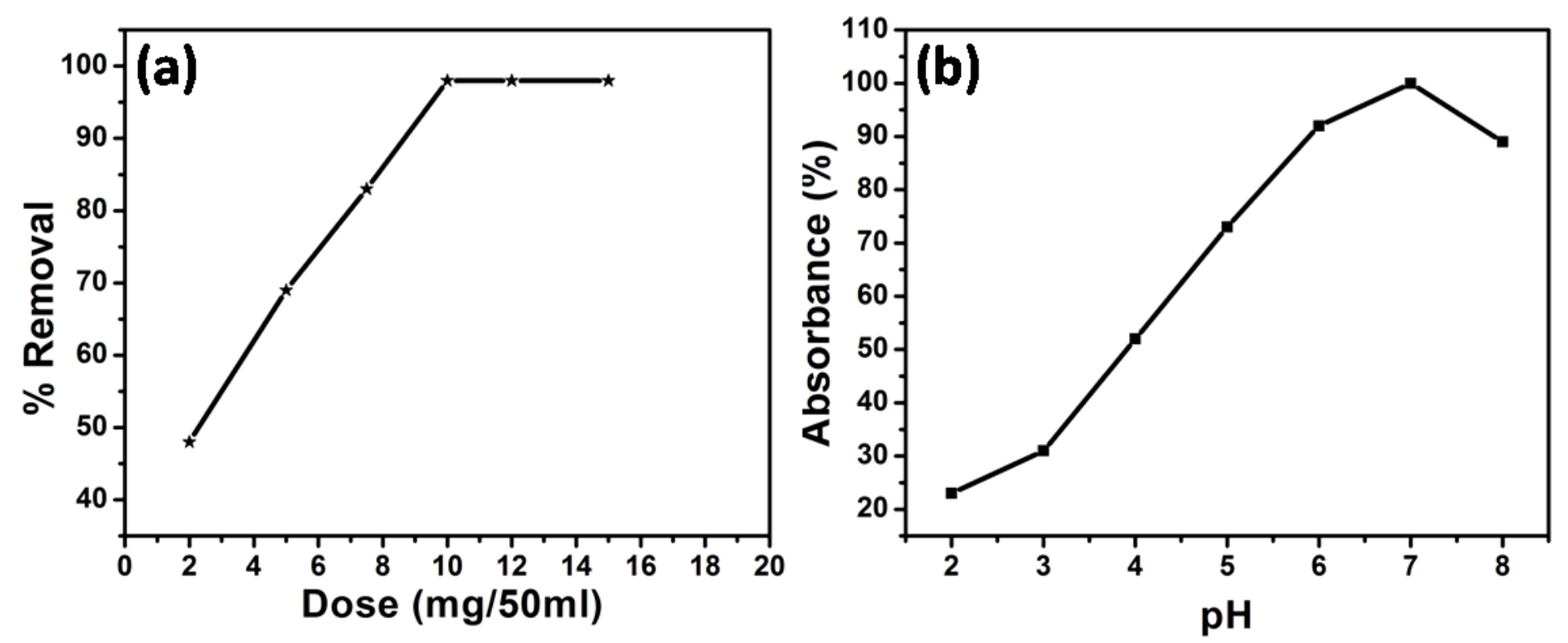
Figure 7

Effect of (a) SBC dose \& (b) pH on degradation
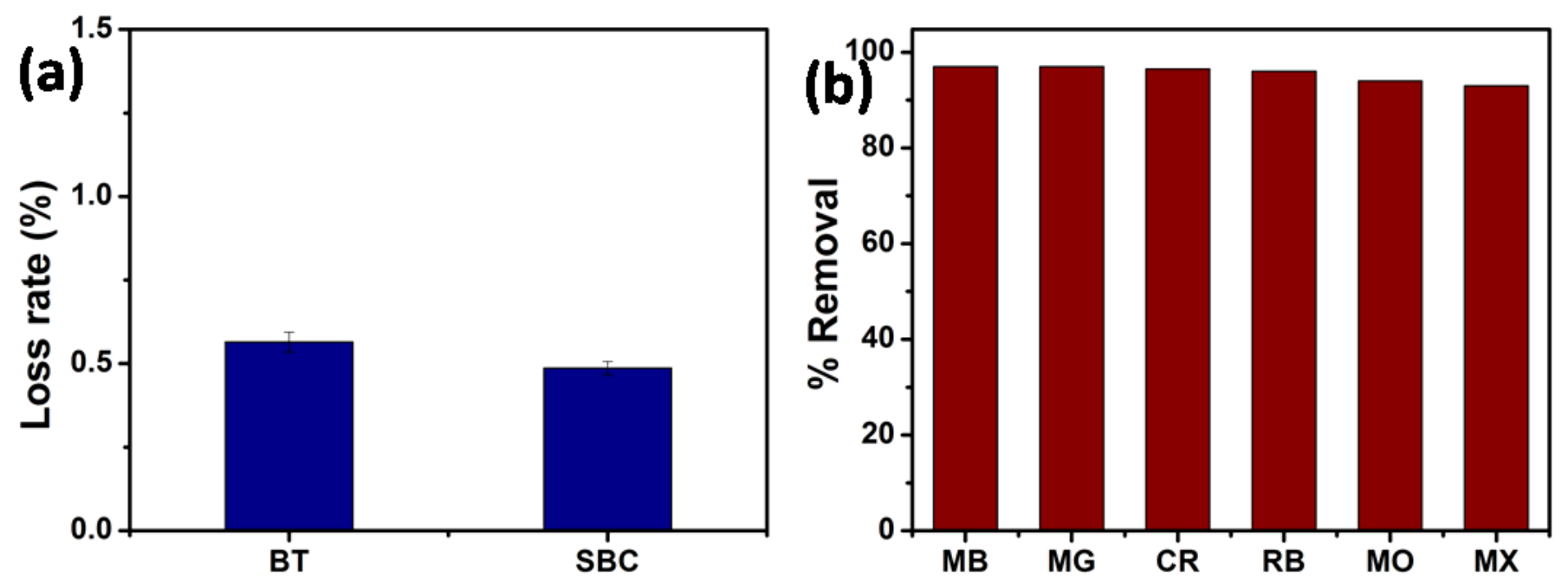

Figure 8

(a) Loss rate \& (b) Reusability of SBC 


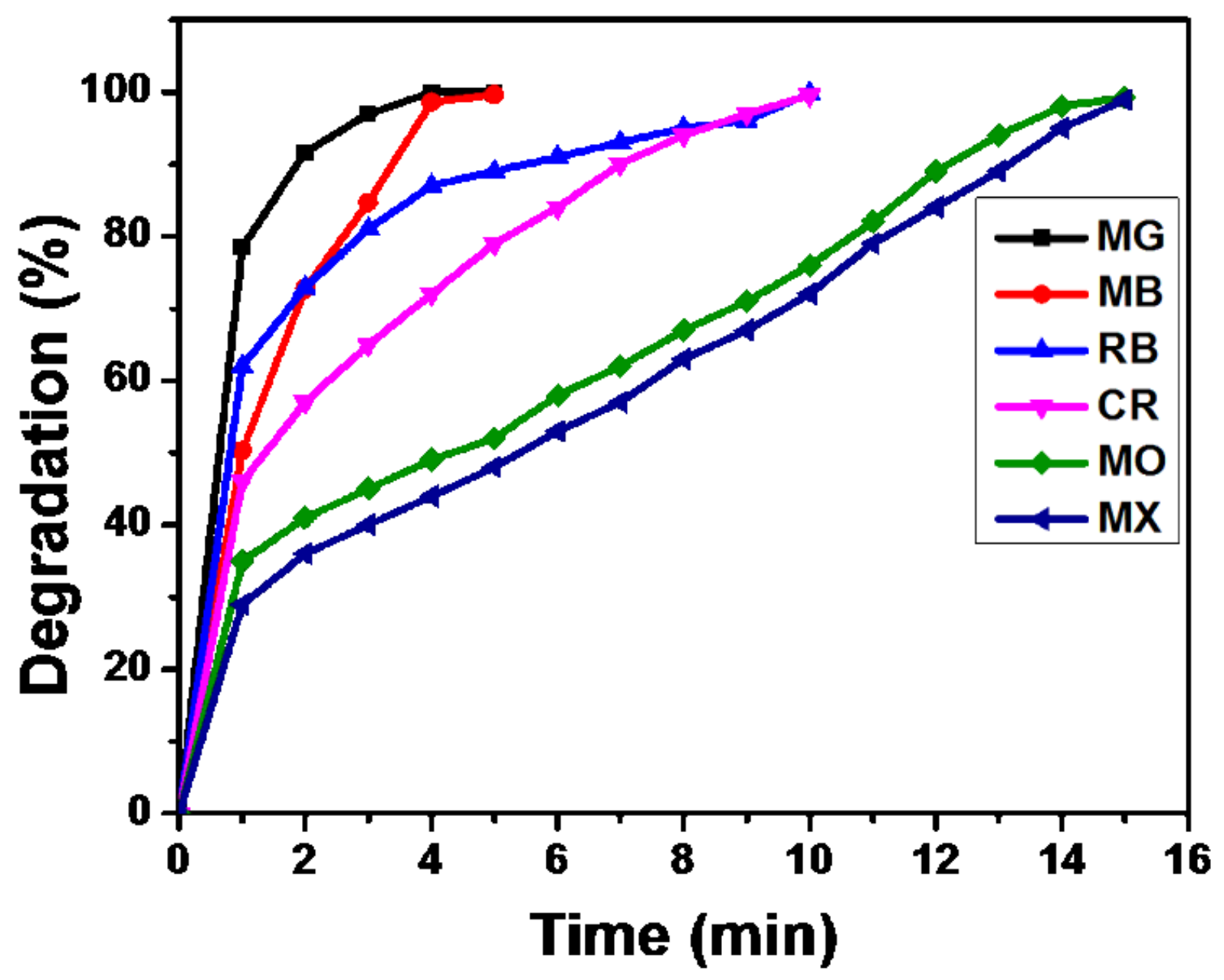

Figure 9

Degradation efficiency of dyes 

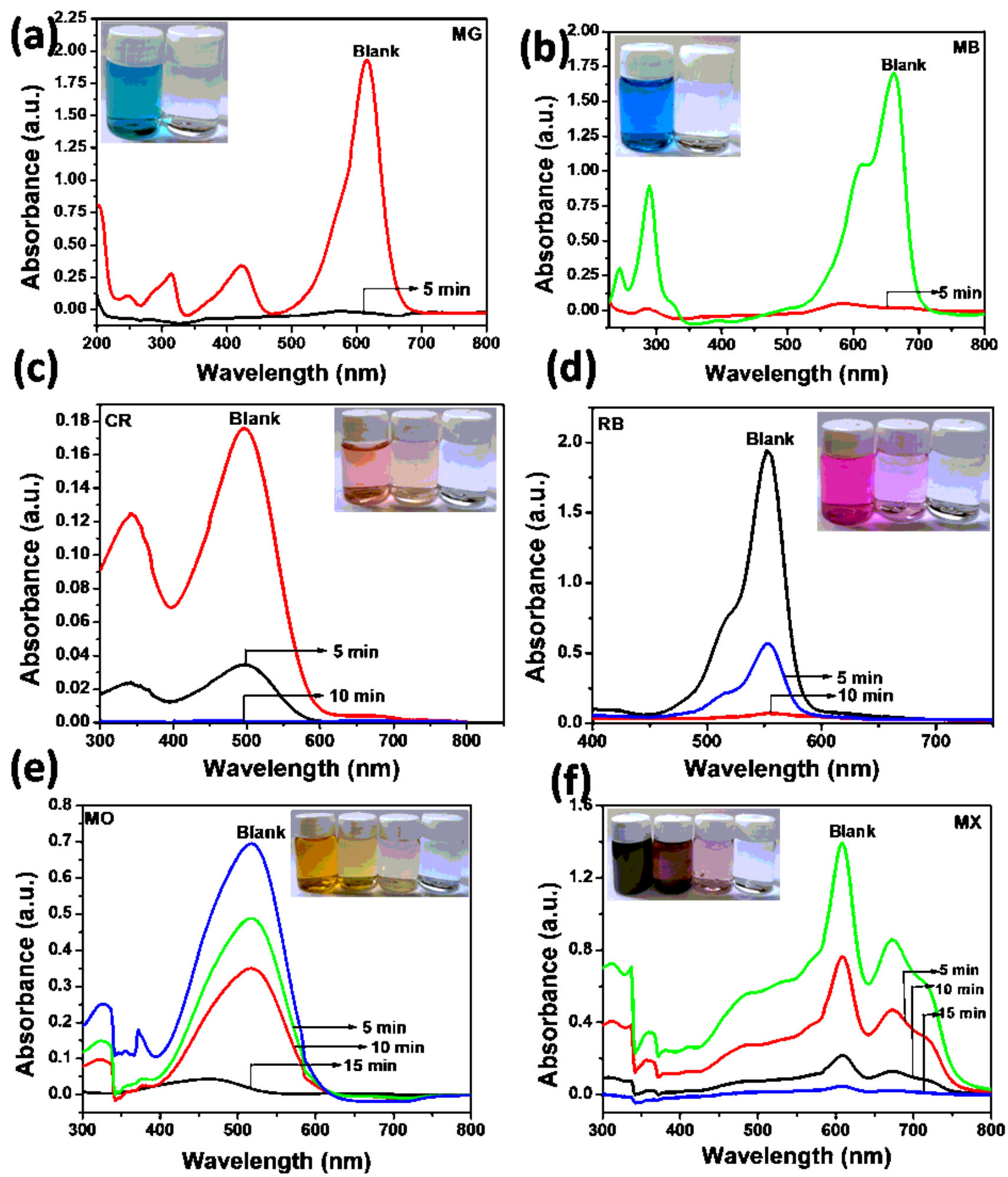

Figure 10

UV-Vis absorption spectra and photographic images of (a) MG, (b) MB, (c) CR, (d) RB, (e) MO \& (f) MX dyes 


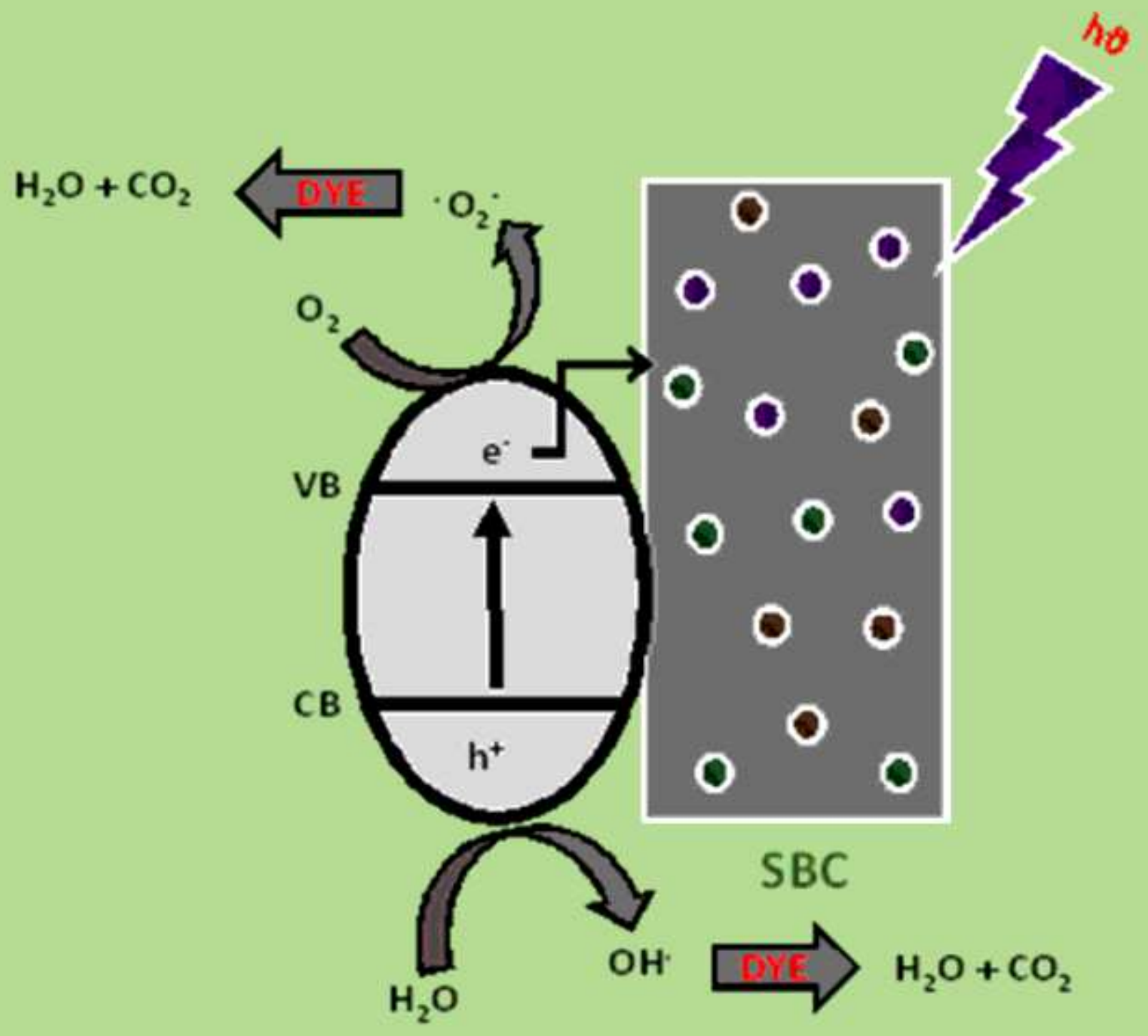

Figure 11

Proposed mechanism of photo degradation 

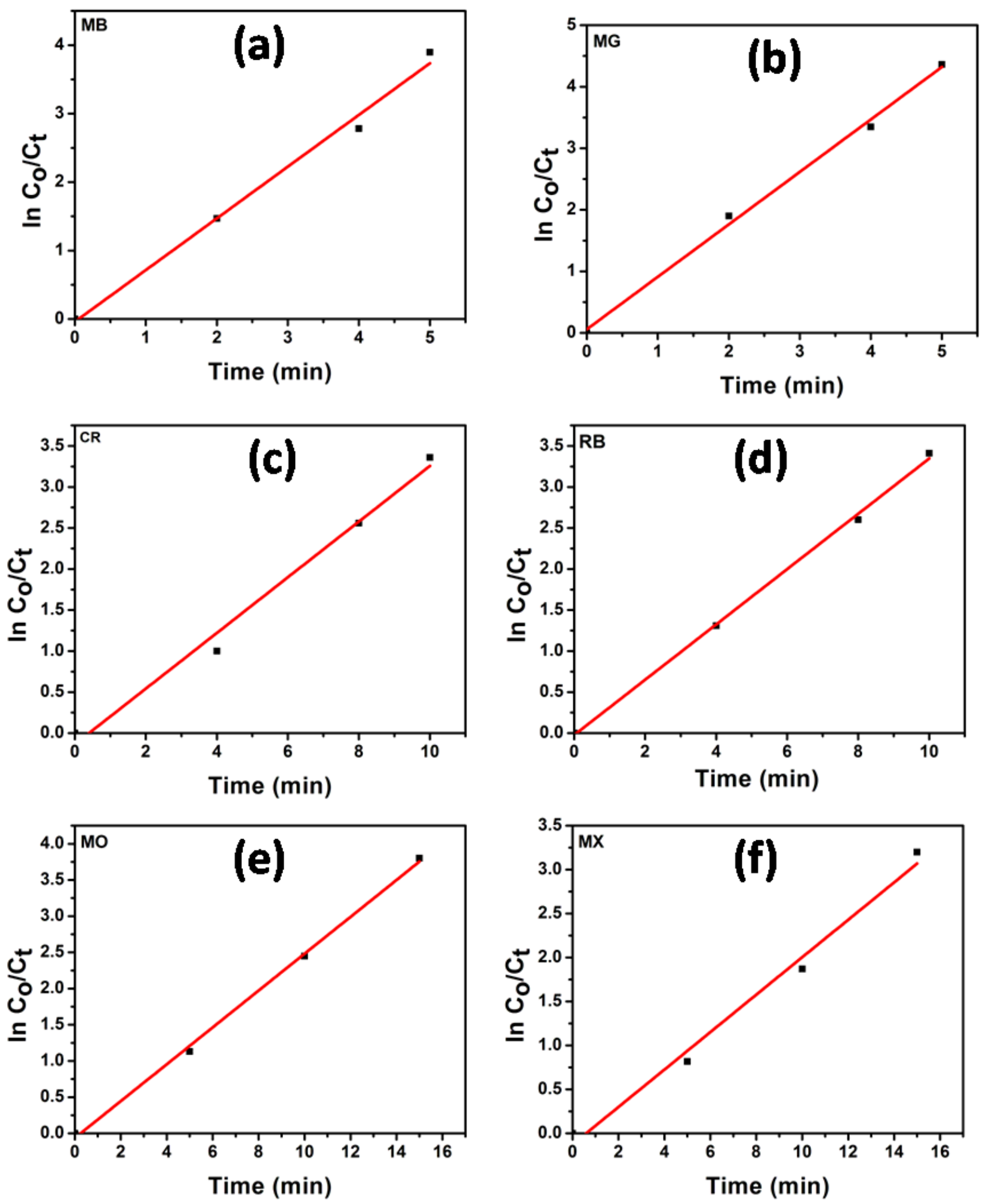

Figure 12

Kinetic plots of (a) MB, (b) MG, (c) CR, (d) RB, (e) MO \& (f) MX 